\title{
Maternal Complications and Adverse Pregnancy Outcomes among Pregnant Women who Acquired Asymptomatic Bacteriuria in Addis Ababa, Ethiopia
}

\author{
Ketema Bizuwork Gebremedhin $\mathbb{D}^{1,2}$ Haile Alemayehu, ${ }^{2}$ Girmay Medhin $\left(\mathbb{D},{ }^{2}\right.$ \\ Wondwossen Amogne $\mathbb{D}^{1},{ }^{1}$ and Tadesse Eguale $\mathbb{\circledR}^{2}$ \\ ${ }^{1}$ College of Health Sciences, Addis Ababa University, Addis Ababa, Ethiopia \\ ${ }^{2}$ Aklilu Lemma Institute of Pathobiology, Addis Ababa University, Addis Ababa, Ethiopia \\ Correspondence should be addressed to Ketema Bizuwork Gebremedhin; ketema.bizuwork@aau.edu.et
}

Received 19 May 2021; Revised 16 July 2021; Accepted 23 July 2021; Published 16 August 2021

Academic Editor: Andrea Maugeri

Copyright (C) 2021 Ketema Bizuwork Gebremedhin et al. This is an open access article distributed under the Creative Commons Attribution License, which permits unrestricted use, distribution, and reproduction in any medium, provided the original work is properly cited.

\begin{abstract}
In this study, we aimed to document adverse pregnancy outcomes and maternal complications among pregnant women who acquired asymptomatic bacteriuria in Addis Ababa, Ethiopia. We used hospital-based prospective cohort study design in which we followed 44 pregnant women with asymptomatic bacteriuria confirmed by urine culture result of $\geq 10^{5} \mathrm{cfu} / \mathrm{ml}$ of urine. We documented adverse pregnancy outcomes and maternal complications in terms of frequency, percentage, mean, and standard deviation. Additionally, we used Pearson's correlation coefficient to investigate associations of selected variables with perinatal death as one of adverse pregnancy outcomes. Of the 44 pregnant women enrolled in the study, complete data was collected from 43 participants with one lost to follow-up. Six (14\%) of women developed fever and were treated with antibiotic during pregnancy, $26(60.5 \%)$ delivered with cesarean section, two $(4.3 \%)$ perinatal deaths within seven days of delivery, one miscarriage, and 4 (9.3\%) newborns were found underweight. The mean birth weight of the newborns was $3.1 \mathrm{~kg} \pm 0.60$. Almost half $21(48.8 \%)$ were born before 37 weeks of gestational age. Fourteen (32.6\%) of newborns were born asphyxiated. Twenty-two (51.2\%) of newborns developed early neonatal fever within 48 hours of delivery and treated with antibiotic. Correlation coefficient analysis revealed that weight and gestational age of newborns at birth, Apgar score at $1^{\text {st }}$ and $5^{\text {th }}$ minutes of birth and miscarriage were positively correlated and significantly associated with perinatal death. The occurrence of unsought pregnancy outcomes were frequent, and substantial number of pregnant women developed maternal complications. Therefore, screening pregnant women for asymptomatic bacteriuria and treating may reduce the possible maternal complications and adverse pregnancy outcomes.
\end{abstract}

\section{Introduction}

Urinary tract infection (UTI) among pregnant women is the most widespread medical problem $[1,2]$. UTI is among most common nosocomial infections [3] that may have significant contribution to the infection among pregnant women. Nosocomial infection would be acquired during either of their follow-up periods, some diagnostic procedures, and/or labor and delivery periods. The main reason that makes pregnant women more susceptible to the infections is pressure of gravid uterus to the bladder and immunologic and urinary tract vicissitudes [4-6] that occur due to physiological changes related to the pregnancy $[6,7]$. Five decades ago, a study revealed prevalence of asymptomatic bacteriuria ranged from 2 to $10 \%$ of all pregnancies [8]; however, some recent studies showed prevalence of asymptomatic bacteriuria ranging from 2 to $15 \%[9,10]$, and even some findings show higher rates of the infection [11-13]. UTI during pregnancy has been linked to increased risk of maternal and neonatal complications [14-17], and the complications are more severe when the women are comorbid with chronic inflammatory diseases, urinary tract abnormalities, autoimmune 
disorders, and other chronic illnesses $[16,18]$. There are evidences that show that untreated urinary tract infection is the common cause of complications like premature rupture of membranes, low birth weight of infant, preterm birth, fetal intrauterine growth restriction, and postpartum endometritis $[7,16,19,20]$. Moreover, previous studies reported that approximately $30-50 \%$ of pregnant women with confirmed pyelonephritis had preterm birth [21-23]. WHO estimated globally, major pregnancy-related complications including UTI accounts for $75 \%$ of maternal deaths, and many of them are preventable [24]. UTI and its complications are more intense in low- and middle-income countries (LMIC) [25]. This might be linked to scarcity of finance and logistics for timely screening of women for the infection [26]. At the same time, it is a less emphasized aspect towards pregnancyrelated morbidity, mortality, and adverse pregnancy outcomes in this region [20]. In Ethiopia, there was no information that describes the effect of asymptomatic bacteriuria in women's health ailments and adverse pregnancy outcomes. However, Ethiopian mini demographic health survey 2019 [27] and other review article revealed [28] that infant mortality rated 77 deaths per 1,000 live births in 2005 which was decreased to 43 deaths per 1,000 live births in 2019 [27, 28]. Additionally, neonatal mortality decreased from 39 to 29 deaths per 1000 live births between 2005 and 2016 and remained steady since 2016 [27, 28]. Furthermore, a review of most predisposing factors of worst pregnancy outcomes showed that mean birth weight of babies born from 19902017 ranges from 2.077 to $3.147 \mathrm{~kg}$ [29]. Another review of literature in Ethiopia reported that pooled prevalence of preterm was $13.32 \%$ [30]. This shows that adverse pregnancy outcomes and maternal complications are still persisting health threats even if they are in declining order during the last decade [27]. In Ethiopia, to the best of our awareness, there is no study that explored adverse pregnancy outcomes and maternal complications related to asymptomatic bacteriuria. The aim of this study was to prospectively follow pregnant women with confirmed asymptomatic bacteriuria in Addis Ababa and explore the type and rate of occurrence of maternal complications and adverse pregnancy outcomes.

\section{Materials and Methods}

2.1. Study Context. The study was conducted in Addis Ababa, the capital city of Ethiopia, [31]. The city is found at above 2400 meters above sea level, $9^{\circ} 1^{\prime} 48 \mathrm{~N} 38^{\circ} \mathrm{C} 44^{\prime} 24^{\prime \prime} \mathrm{E} / 9.03$ degree N 38.7400 degrees east founded by Emperor Menelik at about 1892 [32]. The city has a projected 5,00600 population in 2021 [33]. The country's health delivery system follows the three-tier structure; the secondary and tertiary levels are comprised of general and specialized hospitals, and the coverage of each extends to larger portions of the population. A single tertiary level health care institution gives care for 3-5 million population while secondary level health care sector provides health care for 1-1.5 million population [34]. The city has over forty private hospitals and twelve governmental hospitals. We conducted this study in two governmental (Tikur Anbesa Specialized Hospital and Zewditu Memorial Hospital) and two private Mother and Child
Health Care Specialty Centers (Hemen, and Anania Mother and Child Specialty Centers).

2.2. Study Design and Recruitment of Study Participants. The study design used was hospital-based observational prospective cohort of pregnant women that acquired asymptomatic bacteriuria and consented to be followed for adverse pregnancy outcomes and maternal complications. Initially, we cultured 281 urine of pregnant women with no symptoms of bacteriuria, no history of taking antibiotic two weeks before urine sample collection date, did not take large amount of water one hour before sample collection time, and not have any symptoms of sexually transmitted diseases before urine collection. Then, the forty four pregnant women with urine containing $\geq 10^{5} \mathrm{cfu} / \mathrm{ml}$ of bacteria were considered as having asymptomatic bacteriuria.

2.3. Data Collection Instrument and Quality Control. The data collection tool was prepared from similar literatures and WHO guidelines. Five experts reviewed the quality of the questionnaire, and content validity was determined based on their reports. Accordingly, the content validity index was rated as 0.82 , and appropriate modification was made and clarified for ambiguous items. The data collectors were experienced nurses and midwives working in the antenatal care centers of the study institutions.

2.4. Study Variables and Data Collection Techniques. The data collection techniques that we used were interview and reviewing the chart of the women enrolled in the study. The information was collected within three days of delivery of the followed women. Sociodemographic and maternal background characteristics like maternal age, marital status, educational status, occupation, monthly income per month, frequency of vaginal douching per day, sexual relation per week during this pregnancy period, (history of diabetes mellitus, hypertension, renal calculi, urinary tract infection before this pregnancy), (history gravidity, and parity), treatment for urinary tract infection in this pregnancy, and number of antenatal care visit in the current pregnancy were collected by interview. Maternal clinical characteristics like hemoglobin level before and after delivery, serology test status for HIV/AIDS, HipBSA, and VDRL test result for syphilis in the current pregnancy were reviewed from the chart of the women. Adverse pregnancy outcomes like perinatal death, miscarriage, (weight, length, gestational age at birth), (Apgar score at $1^{\text {st }}$ and $5^{\text {th }}$ minutes of delivery), respiratory distress syndrome and small for gestational age, and early neonatal infection requiring antibiotic within $48 \mathrm{hrs}$ were reviewed from the chart of the women. Maternal complications like postpartum hemorrhage, (prenatal, intrapartum and postpartum period pyrexia requiring antibiotic), mode of delivery, premature rupture of membrane, induction of labor, symptomatic bacteriuria, pregnancy induced hypertension, eclampsia, preeclampsia, premature labor, endometritis, systemic infection, amnionitis, chorioamnionitis, pylonephritis, renal failure, cystitis, septicemia, hyperbilirubinemia requiring treatment, neonatal convulsion, hypoxic ischemic encephalopathy, neonatal encephalopathy, and severe neonatal morbidity were reviewed from the chart of the women. 
2.5. Operational Definitions. Basic terms used in this study were operationalized as follows: maternal complications: complications that may occur during prenatal, labor, delivery, and postnatal period; pregnancy outcomes: results of conception and ensuing pregnancy; asymptomatic bacteriuria: presence of bacteria $\geq 10^{5} \mathrm{cfu} / \mathrm{ml}$ in clean-voided midstream urine specimens of women without symptoms; symptomatic UTI: presence of bacteria greater than or equal to $10^{5} \mathrm{cfu} / \mathrm{ml}$ ) in cleanvoided midstream urine specimens in a women with symptoms; large volume of water: consumption of greater than two glass of water one hour before reaching follow-up center; perinatal death: fetal deaths past 28 completed weeks of pregnancy plus the number of deaths among live-born children up to 7 completed days of life; preterm: fetus born before 37 weeks of gestation; small for gestational age: birth weights below the $10^{\text {th }}$ percentile for babies of the same gestational age; parity: number of delivery; gravidity: number of pregnancy; pregnancy-induced hypertension: new hypertension in a pregnant woman after 20 weeks' of gestation without the presence of protein in the urine; antenatal pyrexia requiring antibiotic: pyrexia treated with antibiotic during antenatal care period; intrapartum fever requiring antibiotic: fever requires antibiotic during labor and delivery period; postpartum fever requiring antibiotic: fever requires antibiotic during postnatal period; induction of labor: use of medications to induce labor; postpartum hemorrhage: excessive bleeding following the birth of a baby; and anemic: hemoglobin $\leq 12 \mathrm{~g} / \mathrm{dl}$.

2.6. Ethical Consideration. Ethical approval was obtained from the Institutional Review Board of Aklilu Lemma Institute of Pathobiology, Addis Ababa University (Ref.No.ALIPBIRB/022/20112019) and from Addis Ababa Health Bureau (Ref. No. A/A/M/36975/227). Permission was obtained from the administration office of each of the study hospitals and heads of antenatal clinics; hereafter, the purpose of the study was clearly explained to the health care professionals working in the antenatal clinics. Verbal consent was obtained from each study participants after detailed information about the study was explained to them. They had also the right to withdraw and/refuse to participate in the study.

2.7. Data Analysis. Data was entered in to Epi-data version 3.1 and exported to SPSS version 22 statistical package software for cleaning, editing, and analysis. Descriptive statistics that include mean, standard deviation, frequency, and percentage were used to summarize the study variables. We used Pearson correlation coefficient to investigate association of selected variables with perinatal death as one measure of outcome. $P$ value $<0.05$ was used to report findings as statistically significant.

\section{Results}

3.1. Sociodemographic and Background Characteristics. Among a total of forty-four pregnant women with acquired asymptomatic bacteriuria, 43 (97.7\%) of them completed their follow-up (Table 1). The majority 27 (62.8\%) were young in the age range of 25 to 34 years, and the mean age was 28 years $(\mathrm{SD}=4.6)$. The majority $42(97.7 \%)$ were married, sixteen
TABLE 1: Sociodemographic, background, and clinical characteristics, $N=43$.

\begin{tabular}{|c|c|}
\hline Variable & Frequency $(\%)$ \\
\hline \multicolumn{2}{|l|}{ Age in years } \\
\hline $15-24$ & $10(23.3)$ \\
\hline $25-34$ & $27(62.8)$ \\
\hline $35-49$ & $6(14)$ \\
\hline \multicolumn{2}{|c|}{ Category of health care center attending } \\
\hline Private & $17(39.5)$ \\
\hline Government & $26(60.5)$ \\
\hline \multicolumn{2}{|l|}{ Current marital status } \\
\hline Married & $42(97.7)$ \\
\hline Unmarried & $1(2.3)$ \\
\hline \multicolumn{2}{|l|}{ Educational status } \\
\hline Not read and write & $1(2.3)$ \\
\hline Read and write & $3(7.3)$ \\
\hline Primary school & $6(16)$ \\
\hline Secondary school & $9(20.9)$ \\
\hline College and above & $24(55.8)$ \\
\hline \multicolumn{2}{|l|}{ Occupation } \\
\hline Unemployed & $31(72.1)$ \\
\hline Employed & $12(27.9)$ \\
\hline \multicolumn{2}{|l|}{ Income per month } \\
\hline$\leq 100 \$$ & $14(32.6)$ \\
\hline$>100 \$$ & $29(67.4)$ \\
\hline \multicolumn{2}{|c|}{ Frequency of vaginal douching per day } \\
\hline$\leq 2 \times$ & $12(28.0)$ \\
\hline $3 \times$ & $31(72.1)$ \\
\hline \multicolumn{2}{|c|}{ History of DM before this pregnancy } \\
\hline Yes & $1(2.3)$ \\
\hline \multicolumn{2}{|c|}{ History of hypertension before this pregnancy } \\
\hline Had & $3(7.0)$ \\
\hline \multicolumn{2}{|c|}{ History of UTI before this pregnancy } \\
\hline Had & $9(20.9)$ \\
\hline \multicolumn{2}{|c|}{ Treated for UTI in this pregnancy } \\
\hline Yes & $13(30.2)$ \\
\hline \multicolumn{2}{|c|}{ Sero-status for HIV/AIDS and/or HipBSA during pregnancy } \\
\hline Positive for HIV/AIDS & $3(7)$ \\
\hline Positive for HipBSA & $6(14)$ \\
\hline \multicolumn{2}{|c|}{ Status of VDRL test during pregnancy } \\
\hline Positive for syphilis & $1(2.3)$ \\
\hline \multicolumn{2}{|c|}{ Anemia status before delivery } \\
\hline Anemic & $22(51.2)$ \\
\hline \multicolumn{2}{|l|}{ Anemia status after delivery } \\
\hline Anemic & $17(39.5)$ \\
\hline
\end{tabular}

(37.2\%) had an experience of having two times sexual contact per week, and $31(72.1 \%)$ had three times vaginal douching per day. Before the current pregnancy, 9 (20.9\%) of the women had history of UTI, and 10 (23.3\%) had renal calculi. More than half $(51.2 \% ; 22 / 43)$ of the pregnant women were anemic in their current pregnancy, their mean hemoglobin 
TABle 2: Pregnancy outcomes and maternal complications among pregnant women, $N=43$.

\begin{tabular}{|c|c|}
\hline Characteristics & Number (\%) \\
\hline \multicolumn{2}{|l|}{ Weight at birth } \\
\hline$<2.5 \mathrm{~kg}$ & $4(9.3)$ \\
\hline $2.5-4.00 \mathrm{~kg}$ & $38(88.4)$ \\
\hline$>4.00 \mathrm{~kg}$ & $1(2.3)$ \\
\hline \multicolumn{2}{|l|}{ GA at birth } \\
\hline$<37$ weeks & $21(48.8)$ \\
\hline $37-40$ weeks & $15(37.9)$ \\
\hline$>40$ weeks & $7(16.3)$ \\
\hline \multicolumn{2}{|l|}{ Length at birth } \\
\hline$\leq 45$ & $25(58.1)$ \\
\hline$>45$ & $18(41.9)$ \\
\hline \multicolumn{2}{|c|}{ Apgar score at 1 minute } \\
\hline$\leq 3$ & $2(4.7)$ \\
\hline $4-6$ & $12(27.9)$ \\
\hline$\geq 7$ & $29(67.4)$ \\
\hline \multicolumn{2}{|c|}{ Apgar score at 5 minutes } \\
\hline$\leq 3$ & $2(4.7)$ \\
\hline $4-6$ & $1(2.3)$ \\
\hline$\geq 7$ & $40(93)$ \\
\hline \multicolumn{2}{|c|}{ Small for gestational age } \\
\hline Yes & $5(11.6)$ \\
\hline \multicolumn{2}{|l|}{ Premature labor } \\
\hline Yes & $7(16.3)$ \\
\hline \multicolumn{2}{|l|}{ Preeclampsia } \\
\hline Yes & $6(14)$ \\
\hline \multicolumn{2}{|l|}{ Eclampsia } \\
\hline Yes & $8(18.6)$ \\
\hline \multicolumn{2}{|c|}{ Pregnancy induced hypertension } \\
\hline Yes & $5(11.6)$ \\
\hline \multicolumn{2}{|c|}{ Had symptomatic for UTI } \\
\hline Yes & $5(11.6)$ \\
\hline \multicolumn{2}{|l|}{ Miscarriage } \\
\hline Yes & $1(2.3)$ \\
\hline \multicolumn{2}{|c|}{ Incidence of antenatal pyrexia requiring antibiotic } \\
\hline Yes & $6(14)$ \\
\hline \multicolumn{2}{|c|}{ Incidence of prelabor rupture of membrane (PROM) } \\
\hline Yes & $26(60.5)$ \\
\hline \multicolumn{2}{|c|}{ Induced to initiate labor } \\
\hline Yes & $31(72.1)$ \\
\hline \multicolumn{2}{|l|}{ Mode of delivery } \\
\hline SDV & $16(37.2)$ \\
\hline OVD & $1(2.3)$ \\
\hline CS & $26(60.5)$ \\
\hline \multicolumn{2}{|c|}{ Intrapartum fever requiring antibiotic } \\
\hline Yes & $11(25.6)$ \\
\hline \multicolumn{2}{|c|}{ Postpartum fever requiring antibiotic } \\
\hline Yes & $27(62.5)$ \\
\hline
\end{tabular}

TABLe 2: Continued.

\begin{tabular}{lc}
\hline Characteristics & Number (\%) \\
\hline $\begin{array}{l}\text { Postpartum hemorrhage } \\
\quad \text { Yes }\end{array}$ & $5(11.6)$ \\
Respiratory distress syndrome & \\
$\quad$ Yes & $2(4.7)$ \\
\hline
\end{tabular}

level before delivery was $12.4(\mathrm{SD}=1.4)$, and their anemia level was reduced by $12 \%$ after delivery with a mean hemoglobin level of $12.5 \pm 2.6$. Nine (20.9\%) of the women were living with HIV/AIDS and/or HipBSA, whereas only one woman was positive and treated for syphilis in the current pregnancy (Table 1).

3.2. Pregnancy Outcome and Maternal Complications. Among the whole pregnant women with ASBU followed for maternal complications and pregnancy outcomes; two (4.3\%) perinatal death and one miscarriage were recorded. Four (9.3\%) of newborns were found underweight while almost half 21 (48.8\%) of newborns were born before 37 weeks of gestational age. Among a total of fourteen (32.6\%) newborns asphyxiated, two of them $(4.7 \%)$ had experienced severe asphyxia at $1^{\text {st }}$ minute; total asphyxia proportion found at $1^{\text {st }}$ minute was reduced to $7 \%$ in the $5^{\text {th }}$ minutes. Regarding maternal complication, seven $(16.3 \%)$, six (14\%), eight (18.6\%), and five $(11.3 \%)$ of the women experienced premature labor, preeclampsia, eclampsia, and pregnancy-induced hypertension, respectively. Five (11.6\%) of the pregnant women who were with ASBU developed symptomatic bacteriuria later on during same pregnancy. Labors of 31 (72.1\%) pregnant women were assisted by induction. The majority $26(60.5 \%)$ of the women delivered by cesarean section (Table 2 ).

3.3. Association of Selected Variables with Perinatal Death. In order to measure association of variables with perinatal death, we used Pearson's correlation coefficient with $P$ value $<0.05$ as a cut off point for significance level. There was no perfect correlation both positively and negatively with perinatal death. However, the positively associated variables: weight, gestational age at birth, Apgar score at first and fifth minutes, and miscarriage were found statistically significantly associated with perinatal death $(P<0.05)$ (Table 3$)$.

\section{Discussion}

In this cohort of 43 pregnant women that acquired ASBU, even if no maternal death was recorded, various adverse pregnancy outcomes were documented. Some of the most prevalent adverse pregnancy outcomes noted were perinatal death, miscarriage, preterm birth, underweight, and asphyxia. Prevalence of perinatal death found in this study is higher by $1.3 \%$ than the global annual neonatal mortality rate [35], which is in line with trends of perinatal mortality in Ethiopia reported previously [36,37]. This indicates that even if mortality of children under 14 years of age is in declining order globally during the last two decades [38], and is promising in Ethiopia [39], the increased perinatal death found by this study is 
TABLe 3: Association of selected variables with perinatal death under Pearson's correlation coefficient, $N=43$.

\begin{tabular}{|c|c|c|}
\hline Variables & Pearson's correlation coefficient & $P$ value \\
\hline Age in years & 0.05 & 0.8 \\
\hline Category of health care center attending & 0.3 & 0.08 \\
\hline Residence & 0.07 & 0.7 \\
\hline Current marital status & 0.03 & 0.8 \\
\hline Educational status & -0.2 & 0.3 \\
\hline Occupation & -0.1 & 0.5 \\
\hline Income per month & 0.08 & 0.6 \\
\hline Frequency of vaginal douching per day & -0.1 & 0.4 \\
\hline Frequency of sexual relation per week & 0.2 & 0.2 \\
\hline History of DM before this pregnancy & -0.03 & 0.03 \\
\hline History of hypertension before this pregnancy & -0.06 & 0.7 \\
\hline History of UTI before this pregnancy & 0.2 & 0.3 \\
\hline Treated for UTI in this pregnancy & -0.1 & 0.4 \\
\hline Serostatus for HIV/AIDS and/or HipBSA during pregnancy & 0.8 & 0.6 \\
\hline Status of VDRL test during pregnancy & -0.03 & 0.8 \\
\hline Anemia status before delivery & 0.1 & 0.4 \\
\hline Anemia status after delivery & 0.2 & 0.2 \\
\hline Weight at birth & 0.4 & 0.02 \\
\hline GA at birth & 0.5 & 0.01 \\
\hline Length at birth & 0.3 & 0.06 \\
\hline Apgar score at $1^{\text {st }}$ minutes & 0.6 & 0.01 \\
\hline Apgar score at $5^{\text {th }}$ minutes & 0.5 & 0.01 \\
\hline Small for gestational age & -0.08 & 0.6 \\
\hline Premature labor & -0.1 & 0.5 \\
\hline Preeclampsia & -0.1 & 0.6 \\
\hline Eclampsia & 0.2 & 0.3 \\
\hline Pregnancy-induced hypertension & -0.1 & 0.6 \\
\hline Had symptomatic for UTI & 0.3 & 0.09 \\
\hline Miscarriage & 0.7 & 0.01 \\
\hline Mode of delivery & 0.05 & 0.7 \\
\hline PROM & -0.1 & 0.5 \\
\hline Induced to initiate labor & -0.1 & 0.5 \\
\hline Antenatal pyrexia requiring antibiotic & -0.1 & 0.6 \\
\hline Intrapartum fever requiring antibiotic & 0.1 & 0.4 \\
\hline Postpartum fever requiring antibiotic & 0.2 & 0.3 \\
\hline Postpartum hemorrhage & 0.3 & 0.1 \\
\hline Respiratory distress syndrome & -0.05 & 0.8 \\
\hline
\end{tabular}

bothersome. This could be due to uropathogens causing bacteriuria leading to adverse pregnancy outcomes through competing to nutrients, alteration of absorption of nutrients, and their metabolic mechanism [40-43] that would vanish immune functions of the women [43] resulting in fetomaternal complications [44]. Likewise, this study found four (9.3\%) underweight, equated to be 90 low birth weight per 1000 births. This indicates high prevalence of low birth weight while the government and concerned stakeholders are endeavoring more to reduce by $30 \%$ until 2025 as targeted by WHO [45]. This finding is in line with the global prevalence of low birth weight (3-15\%) [46] and Latin America (9\%) [45] and Italy [41]. However, it is lower by $3.7 \%$ and $18.7 \%$ from subSaharan African and South Asian countries, respectively [45]. This pointed out a promising decline of low birth weight in Ethiopia compared to other regions. However, it is still high compared to global prevalence of low birth weight level [46]. This may be due to the newborns born to women who acquired asymptomatic bacteriuria during their pregnancy states. Therefore, bearing in mind, the consequences of low birth weight $[47,48]$ its haunting cause $[36,49,50]$ including urinary tract infection [51], it is important to follow explicit 
intercession to reduce the prevalence of low birth weight in the country, which ultimately reduces prevalence of perinatal deaths $[52,53]$ and newborn-related complications $[53,54]$.

It is universal fact that preterm birth is fundamental causes of perinatal death [55], the global prevalence of preterm birth is $9.6 \%$ in 2005 [55], which still persists to $11 \%$ [56] in 2020. Here, this study found prevalence of preterm newborns born to women with ASBU while pregnant women were almost $4.4 \%$ times higher than the global estimated burden of preterm births [56]. In fact, finding of this study revealed lower prevalence of preterm birth when compared to report from sub-Saharan African and South Asian countries [57]. This indicates, even if finding of this study is promising compared to that of sub-Saharan and South Asian countries, it shows significant variation with the global burden of preterm birth burden. This may be due to the fact that preterm birth might be due to the complication resulting from ASBU during pregnancy [51]. Apgar score both at $1^{\text {st }}$ minute of delivery and $5^{\text {th }}$ minute has ground role in the survival rate and/or perinatal death of the newborns [58]. In this study, one out of three newborns was asphyxiated in their first minutes of birth, of which five percent of them were severely asphyxiated. Five minutes later, while almost all moderately asphyxiated newborns were relieved from their asphyxia, the severely asphyxiated newborns persisted with the asphyxia state found at birth. The two perinatal deaths reported in this study were those that had asphyxia that persisted after five minutes of delivery. This may perhaps be related to the precomorbidity of the women with other diseases while pregnant in addition to the known asymptomatic bacteriuria. This finding is two times higher than birth asphyxia revealed by study in the southern part of Ethiopia [59] and higher by $10.5 \%$ from study conducted in the northern part of Ethiopia [60], in line with another study from southern part of Ethiopia [61]. The higher prevalence of birth asphyxia found in this study may be due to the women being with ASBU and/or may be due to other comorbidities.

A significant number of pregnant women followed were found having delayed natural initiation of labor and required induction artificially. This may be due to the effect of comorbidity of the women with infectious diseases like symptomless bacteriuria that affects the endometrium.

Therefore, having in mind, the high rate of perinatal death and other maternal and newborn-related complications, it is essential to encourage and increase awareness of pregnant women at large the way to be healthy for both mother and fetus during prenatal, intrapartum and postnatal periods. At its instant point, first, pregnant women should increase the number of prenatal cares until delivery that helps the chance of identifying comorbidities, especially those with no symptoms like asymptomatic bacteriuria that may result in a number of adverse pregnancy outcomes as a hidden factor. Second, the health care professionals assigned in the prenatal care unit should always be up-to-date with recent updates of science in regards to their working areas and should try to identify pregnancy-related comorbidities and complications. Third, health care professionals assigned in the prenatal, perinatal, and postnatal care units should assess for each factor related to pregnancy complications in each visit of the pregnant women for care. The study has its own limitations, like small sample size that might not enable us to generalize to the wider population, and we recommend additional study with larger sample size and wide study area.

\section{Conclusion}

We documented numerous maternal and adverse pregnancy outcomes from the follow-up of pregnant women diagnosed with asymptomatic bacteriuria. The most common is perinatal death and immature labor which was supported by induction. Under weight, gestational age, Apgar score at first and fifth minutes, and miscarriage were found factors positively allied to the perinatal death. Therefore, there should be an intervention that handles the maternal complications and adverse pregnancy outcomes especially by focusing to the unseen comorbidities like asymptomatic bacteriuria. However, as the outcomes were recorded from only pregnant women with ASBU by not excluding other comorbidities, further follow-up study with the control group and larger sample size is recommended.

\section{Abbreviations}

Apgar: $\quad$ A: appearance, $\mathrm{P}$ : pulse rate, G: grimace, A:

ASBU: $\quad$ Astivity, R: respiration

CS: $\quad$ Cesarean section

DM: Diabetes mellitus,

G/DL: $\quad$ Gram per deciliter

GA: Gestation age

HiBSA: Hepatitis B surface antigen

HIV/AIDS: Human immunodeficiency virus/acquired immunodeficiency syndrome

IRB: Institutional review board

LMIC: $\quad$ Low- and middle-income countries

OVD: $\quad$ Operative vaginal delivery

PROM: $\quad$ Premature rupture of membrane

SVD: $\quad$ Spontaneous vaginal delivery

UTI: Urinary tract infection

VDRL: Venereal Disease Laboratory Research

WHO: World Health Organization.

\section{Data Availability}

The data will be available from the corresponding author upon request.

\section{Conflicts of Interest}

All authors declared that they have no conflict of interest.

\section{Acknowledgments}

This study was supported by Thematic Research Project of Addis Ababa University. We are grateful for the leaders of health care institutions included in the study for their support and study participants for their cooperation. 


\section{References}

[1] M. Mahmoud, A. Kamel, S. Ahmed, and A. El-Hamed, "Prevalence of urinary tract infections among pregnant women at Sohag University Hospital," Egyptian Nursing Journal, vol. 16, pp. 162-174, 2019.

[2] M. Younis, S. Ajroud, L. Elgade, A. Uahua, and R. Elzahaf, "Prevalence of urinary tract infection among pregnant women and its risk factor in Derna City," Scholars International Journal of Obstetrics and Gynecology, vol. 8, pp. 219-223, 2019.

[3] M. Barchitta, A. Maugeri, G. Favara et al., "Cluster analysis identifies patients at risk of catheter-associated urinary tract infections in intensive care units: findings from the SPINUTI Network," The Journal of Hospital Infection, vol. 107, pp. 57-63, 2021.

[4] K. L. Cheung and R. A. Lafayette, "Renal physiology of pregnancy," Advances in Chronic Kidney Disease, vol. 20, no. 3, pp. 209-214, 2013.

[5] J. E. Delzell Jr. and M. L. Lefevre, "Urinary tract infections during pregnancy," American Family Physician, vol. 61, no. 3, pp. 713-721, 2000.

[6] R. S. Remis, M. J. Gurwith, D. Gurwith, N. T. Hargrett-Bean, and P. M. Layde, "Risk factors for urinary tract infection," American Journal of Epidemiology, vol. 126, no. 4, pp. 685694, 1987.

[7] S. R. Dimetry, H. M. El-Tokhy, N. M. Abdo, M. A. Ebrahim, and M. Eissa, "Urinary tract infection and adverse outcome of pregnancy," The Journal of the Egyptian Public Health Association, vol. 82, pp. 203-218, 2007.

[8] P. Whalley, "Bacteriuria of pregnancy," American Journal of Obstetrics and Gynecology, vol. 97, no. 5, pp. 723-738, 1967.

[9] D. S. Ipe, L. Sundac, W. H. Benjamin Jr., K. H. Moore, and G. C. Ulett, "Asymptomatic bacteriuria: prevalence rates of causal microorganisms, etiology of infection in different patient populations, and recent advances in molecular detection," FEMS Microbiology Letters, vol. 346, no. 1, pp. 1-10, 2013.

[10] A. Masinde, B. Gumodoka, A. Kilonzo, and S. E. Mshana, "Prevalence of urinary tract infection among pregnant women at Bugando Medical Centre, Mwanza, Tanzania," Tanzania journal of health research, vol. 11, no. 3, pp. 154-159, 2009.

[11] A. Ranjan, S. T. Sridhar, N. Matta, S. Chokkakula, and R. K. Ansari, "Prevalence of UTI among pregnant women and its complications in newborns," Indian Journal of Pharmacy practice, vol. 10, no. 1, pp. 45-49, 2017.

[12] E. Tadesse, M. Teshome, Y. Merid, B. Kibret, and T. Shimelis, "Asymptomatic urinary tract infection among pregnant women attending the antenatal clinic of Hawassa Referral Hospital, southern Ethiopia," BMC Research Notes, vol. 7, no. 1, p. 155, 2014.

[13] P. E. Imade, P. E. Izekor, N. O. Eghafona, O. I. Enabulele, and E. Ophori, "Asymptomatic bacteriuria among pregnant women," North American Journal of Medical Sciences, vol. 2, no. 6, pp. 263-266, 2010.

[14] F. J. Garcia and A. L. Nager, "Jaundice as an early diagnostic sign of urinary tract infection in infancy," Pediatrics, vol. 109, no. 5, pp. 846-851, 2002.

[15] N. Khalesi, T. Shahraki, and M. M. Haghighi, "Prevalence of urinary tract infection in neonates with prolonged jaundice referred to Aliasghar Hospital in Zahedan (2005)," The Journal of Qazvin University of Medical Sciences, vol. 11, pp. 14-18, 2007.
[16] A. T. Beksac, G. Orgul, A. Tanacan et al., "Uropathogens and gestational outcomes of urinary tract infections in pregnancies that necessitate hospitalization," Current urology, vol. 13, no. 2, pp. 70-73, 2019.

[17] K. Loh and N. Sivalingam, "Urinary tract infections in pregnancy," Malaysian family physician: the official journal of the Academy of Family Physicians of Malaysia, vol. 2, no. 2, pp. 54-57, 2007.

[18] M. Fridman, L. M. Korst, J. Chow, E. Lawton, C. Mitchell, and K. D. Gregory, "Trends in maternal morbidity before and during pregnancy in California," American Journal of Public Health, vol. 104, Suppl 1, pp. S49-S57, 2014.

[19] L. Yan, Y. Jin, H. Hang, and B. Yan, “The Association between Urinary Tract Infection during Pregnancy and Preeclampsia: A Meta-Analysis," Medicine, vol. 97, no. 36, p. e12192, 2018.

[20] N. M. Gilbert, V. P. O'Brien, S. Hultgren, G. Macones, W. G. Lewis, and A. L. Lewis, "Urinary tract infection as a preventable cause of pregnancy complications: opportunities, challenges, and a global call to action," Global advances in health and medicine, vol. 2, no. 5, pp. 59-69, 2013.

[21] J. B. Hill, J. S. Sheffield, D. D. McIntire, and G. D. Wendel, "Acute Pyelonephritis in Pregnancy," Obstetrics \& Gynecology, vol. 105, no. 1, pp. 18-23, 2005.

[22] E. H. Kass, "Pyelonephritis and Bacteriuria," Annals of Internal Medicine, vol. 56, no. 1, pp. 46-53, 1962.

[23] R. Romero, E. Oyarzun, M. Mazor, M. Sirtori, J. C. Hobbins, and M. Bracken, "Meta-analysis of the relationship between asymptomatic bacteriuria and preterm delivery/low birth weight," Obstetrics and Gynecology, vol. 73, no. 4, pp. 576582, 1989.

[24] T. B. Firm, Top 5 causes of Maternal deaths in the U.S, 2021, https://www.beasleyfirm.com/blog/2021/.

[25] A. C. C. Lee, L. C. Mullany, A. K. Koffi et al., "Urinary tract infections in pregnancy in a rural population of Bangladesh: population-based prevalence, risk factors, etiology, and antibiotic resistance," BMC Pregnancy and Childbirth, vol. 20, p. 1, 2019.

[26] WHO, Recommendations on antenatal care for a positive pregnancy experience, 2016, https://apps.who.int/iris/bitstream/ handle/10665/250796/9789241549912-eng.pdf;jsessionid= 981DD83FF1364E70C9915FB6CBAD540A? sequence $=1$.

[27] Ethiopian Federal Ministry of Health, Ethiopian mini demographic health survey, 2019, https://dhsprogram.com/pubs/ pdf/PR120/PR120.pdf.

[28] K. F. Muchie, A. M. Lakew, D. F. Teshome et al., "Prevalence and associated factors of preterm birth in Ethiopia: systematic review and meta-analysis protocol," BMJ Open, vol. 10, no. 5, article e035574, 2020.

[29] N. A. Katiso, G. M. Kassa, G. A. Fekadu, A. Kidanemariam Berhe, and A. A. Muche, "Prevalence and determinants of low birth weight in Ethiopia: a systematic review and metaanalysis," Advances in Public Health, vol. 2020, Article ID 7589483, 13 pages, 2020.

[30] G. Mulualem, A. Wondim, and A. Woretaw, "The effect of pregnancy induced hypertension and multiple pregnancies on preterm birth in Ethiopia: a systematic review and metaanalysis," BMC Research Notes, vol. 12, no. 1, p. 91, 2019.

[31] U. W. Tolon, "Ethiopia and Its Capital Addis Ababa," 2008, https://upcommons.upc.edu/bitstream/handle/2099.1/6374/ 07.pdf? sequence $=8$. 
[32] The Editors of Encyclopedia Britannica, "Addis Ababa Encyclopædia Britannica,” 2019, https://www.britannica.com/ place/Addis-Ababa.

[33] Macrotrends, "Addis Ababa, Ethiopia Metro Area Population 1950-2021,” 2021, https://www.macrotrends.net/cities/20921/ addis-ababa/population.

[34] WHO, "Primary health care system in Ethiopia," 2017, https:// www.who.int/alliance-hpsr/projects/alliancehpsr_ ethiopiaabridgedprimasys.pdf.

[35] WHO, "Child-mortality-report," WHO, 2019, https://www .unicef.org/media/60561/file/UN-IGME-child-mortalityreport.

[36] B. H. Jena, G. A. Biks, K. A. Gelaye, and Y. K. Gete, "Magnitude and trend of perinatal mortality and its relationship with inter-pregnancy interval in Ethiopia: a systematic review and meta-analysis," BMC Pregnancy and Childbirth, vol. 20, no. 1, p. 432, 2020.

[37] Y. Berhan and A. Birhan, "Perinatal mortality trends in Ethiopia," Ethiopian Journal of Health Sciences, vol. 24, p. 29, 2014.

[38] A. K. Andegiorgish, M. Andemariam, S. Temesghen, L. Ogbai, Z. Ogbe, and L. Zeng, "Neonatal mortality and associated factors in the specialized neonatal care unit Asmara, Eritrea," BMC Public Health, vol. 20, no. 1, p. 10, 2020.

[39] A. S. Susuman, "Child mortality rate in Ethiopia," Iranian Journal of Public Health, vol. 41, no. 3, pp. 9-19, 2012.

[40] A. C. Ross, C. L. Taylor, A. L. Yaktine, and H. B. ValleDel, Eds., Institute of Medicine (US) Committee to Review Dietary Reference Intakes for Vitamin D and Calcium, National Academies Press (US), Washington (DC), 2011.

[41] M. Barchitta, A. Maugeri, M. C. La Rosa et al., "Single nucleotide polymorphisms in vitamin $\mathrm{D}$ receptor gene affect birth weight and the risk of preterm birth: results from the "Mamma \& Bambino" cohort and A meta-analysis," Nutrients, vol. 10, no. 9, p. 1172, 2018.

[42] Community College of Baltimore county The Ability to Compete for Nutrients, 2021, https://bio.libretexts.org/@go/page/ 3163.

[43] N. Kedia-Mehta and D. K. Finlay, "Competition for nutrients and its role in controlling immune responses," Nature Communications, vol. 10, no. 1, p. 2123, 2019.

[44] D. J. Jamieson, R. N. Theiler, and S. A. Rasmussen, "Emerging infections and pregnancy," Emerging Infectious Disease journal, vol. 12, no. 11, pp. 1638-1643, 2006.

[45] WHO, Global Nutrition Targets 2025, 2014, https://apps.who .int/iris/bitstream/handle/10665/149020/WHO_NMH_ NHD_14.5_eng.pdf?ua=1.

[46] A. Talie, M. Taddele, and M. Alemayehu, "Magnitude of low birth weight and associated factors among newborns delivered in Dangla Primary Hospital, Amhara Regional State, Northwest Ethiopia, 2017," Journal of Pregnancy, vol. 2019, Article ID 3587239, 6 pages, 2019.

[47] G. Kayode, M. Amoakoh-Coleman, I. Agyepong, E. Ansah, D. Grobbee, and K. Klipstein-Grobusch, "Contextual risk factors for low birth weight: a multilevel analysis," PLoS One, vol. 9, no. 10, article e109333, 2014.

[48] C. A. Negrato and M. B. Gomes, "Low birth weight: causes and consequences," Negrato and Gomes Diabetology \& Metabolic Syndrome, vol. 2, p. 5, 2013.
[49] J. Siza, "Risk Factors Associated with Low Birth Weight of Neonates among Pregnant Women Attending a Referral Hospital in Northern Tanzania," Tanzania Journal of Health Research, vol. 10, no. 1, pp. 1-8, 2008.

[50] T. Tema, "Prevalence and determinants of low birth weight in Jimma Zone, Southwest Ethiopia," East African Medical Journal, vol. 83, no. 7, pp. 366-371, 2006.

[51] J. N. Krieger, "Complications and treatment of urinary tract infections during pregnancy," The Urologic Clinics of North America, vol. 13, no. 4, pp. 685-693, 1986.

[52] WHO, Review of and classification of causes of perinatal death (ICD-PM), 2016, https://www.healthynewbornnetwork.org/ hnn-content/uploads/Review-of-and-classification-of-causesof-perinatal-death.pdf.

[53] M. F. Steve, E. C. Laura, O. D. Mercedes et al., Childhood and maternal underweight, 2016, https://www.who.int/ publications/cra/chapters/volume1/0039-0162.pdf.

[54] T. Toru and W. Anmut, "Assessment of low birth weight and associated factors among neonates in Butajira General Hospital, South Ethiopia, cross sectional study, 2019," International Journal Of Pediatrics, vol. 2020, Article ID 5841963, 6 pages, 2020.

[55] J. P. Vogel, S. Chawanpaiboon, A. B. Moller, K. Watananirun, M. Bonet, and P. Lumbiganon, "The global epidemiology of preterm birth," Best Practice \& Research. Clinical Obstetrics \& Gynaecology, vol. 52, pp. 3-12, 2018.

[56] S. R. Walani, "Global burden of preterm birth,” International Journal of Gynecology \& Obstetrics, vol. 150, no. 1, pp. 31-33, 2020.

[57] USAID, Profile of Preterm and Low Birth Weight Prevention and Care, 2017, https://www.healthynewbornnetwork.org/ hnn-content/uploads/Ethiopia20171.pdf.

[58] Z. Billimoria, S. Chabra, A. Patel, M. M. Gray, R. Umoren, and T. Sawyer, "Apgar score of 0 at $10 \mathrm{~min}$ and survival to 1 year of age: a retrospective cohort study in Washington state," Journal of Perinatology, vol. 39, no. 12, pp. 1620-1626, 2019.

[59] R. A. Abdo, H. M. Halil, B. A. Kebede, A. A. Anshebo, and N. G. Gejo, "Prevalence and contributing factors of birth asphyxia among the neonates delivered at Nigist Eleni Mohammed memorial teaching hospital, southern Ethiopia: a cross-sectional study," BMC Pregnancy and Childbirth, vol. 19, no. 1, p. 536, 2019.

[60] G. Gebreheat, T. Tsegay, D. Kiros et al., "Prevalence and associated factors of perinatal asphyxia among neonates in general hospitals of Tigray, Ethiopia, 2018," BioMed Research International, vol. 2018, Article ID 5351010, 7 pages, 2018.

[61] A. Alemu, G. Melaku, G. B. Abera, and A. Damte, "Prevalence and associated factors of perinatal asphyxia among newborns in Dilla University referral hospital, southern Ethiopia2017," Pediatric health, medicine and therapeutics, vol. Volume 10, pp. 69-74, 2019. 